\title{
Classifying Approaches to Object Oriented Analysis of Work with Activity Theory
}

\author{
Ole Smørdal \\ Department of Informatics, University of Oslo \\ Published in Orlowska ME and Zicari R (eds.) 4th International Conference on \\ Object-Oriented Information Systems (OOIS'97) (Brisbane, Australia), Springer- \\ Verlag.
}

\begin{abstract}
There is a need to use object orientation to analyse work practices. This should be done based on a social theory on how computers mediate the work arrangement. This paper presents a conceptual framework based on activity theory in which two main schools of object oriented modelling are explained. Thus, several object oriented analysis approaches may be combined and contribute to more powerful representational forms.
\end{abstract}

Keywords: Collective work, Physical modelling, Role Modelling

\section{Introduction}

Various object oriented (OO) approaches have been used to analyse the real-world domain that the computer system is intended to maintain information about. Lately, object oriented approaches have also been used to capture aspects beyond this domain, and address the usage world, e.g., aspects relating to actors, communication, articulation of work, collective work, task flow, and work procedures (see e.g., Høydalsvik and Sindre 1993; Jacobson, et al. 1994; Bürkle, et al. 1995; Carstensen, et al. 1995; Krogh 1996). This is due to a shift of perspectives regarding the role of the computer in work settings; from a focus on the computer as means of control and administration of a 
real-world domain, to a focus that also include the computer as a mediator in the usage world, e.g., as in groupware or workflow applications.

Kaasbøll and Smørdal (1996) argue that this shift of perspectives has not been accompanied with extensions of the theoretical foundation for object oriented modelling. This is a problem for 'pure' object oriented approaches, because $\mathrm{OO}$ is a universal approach, and not particularly targeted toward analysis of the usage world. Therefore, many approaches combine $\mathrm{OO}$ with some other perspective, like a metaphor, a framework, or a theory that address work.

An important lesson from the Scandinavian systems development research tradition is that no single perspective is sufficient when relating to a complex situation. Rather, a multi perspective approach is necessary (see e.g. Nygaard 1986; Nygaard and Sørgaard 1987). Various OO methods and techniques address different aspects of work, hence a multi perspective approach seems easy to accomplish. However, selection and combination of the approaches may be difficult, due to differences in scope, concepts and inherent perspectives.

My contribution is thus not another technique or method, but a theoretical framework addressing object oriented analysis (OOA) of computers mediating collective activity. This framework is used to classify OOA approaches, in terms of what aspects of work they address. The framework is based on activity theory (Leontjev 1983; Engeström 1987; Fjuk, et al. forthcoming), and is here used as a bridging link between the social concerns and the technical concerns as it addresses human work in a social context and has a strong emphasis on how artefacts (like computer systems) mediate human activity.

The framework integrates activity theory and two schools of object oriented modelling, here denoted the physical modelling school and the role modelling school. Six selected object oriented approaches are explained using the framework, thus enabling comparing and contrasting the approaches.

The paper is structured as follows: The rest of the introduction presents the research approach for this work. Representations related to work arrangements are presented in Section 2. Section 3 presents an activity theoretical perspective on work. Section 4 
presents the explanation of object oriented analysis in terms of activity theory. Six approaches to OOA are classified in terms of the framework in Section 5. Section 6 concludes the paper.

\subsection{Research Approach}

The method used in this work is presented and discussed by Kaasbøll and Smørdal (1996), who argues that object oriented modelling techniques should be developed according to knowledge about human work within organisations. In order to point to how to bring such knowledge into the process of developing techniques, a learning cycle consisting of practice, evaluation, theoretical contribution, and suggestion of improved techniques is outlined.

In order to develop the techniques such that they can model issues related to work, knowledge of work has to be included in the ways modelling problems are explained and new modelling mechanisms are suggested. Therefore, the theoretical scope of development of techniques should be widened from the focus on formal and implementation considerations to a system development research learning cycle that is open for any contribution to understanding the domain that is to be modelled. It is argued that the perspective on work is fundamental to the selection and development of theoretical foundations for modelling. (ibid.).

According to the learning cycle, the problems addressed in this paper are on a theoretical level. The work reported is a reflection upon problems a group of information systems researchers faced doing a needs assessment for a municipal agency in Norway dealing with town planning, building permits, and geodata (see Smørdal 1996 for details on this study).

\section{Representations of Work}

To be precise in the further discussion, I first define areas that can be modelled during system development, based on similar concepts in Mathiassen et al. (1993).

- The problem domain of a computer system is what the computer system is about; the part of the world that the computer system is supposed to handle, control or monitor. Examples (with basic components): a flight booking system (flights, seats, reservations, customers), a banking system (customers, transactions, accounts, loans, interests). 
- The application domain of a computer system consists of the users, the organisational context, and the work in which the computer system is used, e.g., a travel agency, a bank. Elements of the application domain are employees, the coordination of work, communication, power structures, ad-hoc organised work, interruptions in work, etc.

- The computer system including its application program, data/ object base, user interface module, and communication modules.

When analysing functionality requirements of a system, one could make a model of the application domain. Since it is assumed that the problem domain is more stable than the functional requirement, making an object-oriented model of the application domain is often not considered worthwhile.

A model of the future computer system will often be an extension of a model of the problem domain in order to include software modules and objects needed for implementation.

As mentioned in the introduction, a shift in the perspective in respect to the roles the computer systems may play in human work within organisations have been noticed. Earlier, a common view of the computer was that it was used for handling or controlling a problem domain, hence the models did not address elements in the application domain explicitly. Lately there has been an increasing attention in both system development practice and in the research community toward using the computer as a medium in the work organisation, thus enabling the use of computers as means of coordinating work and communication in and about work. (e.g. in the field of CSCW, see Simone and Schmidt 1993; Carstensen, et al. 1995). This implies that issues of the application domain need to be included in the models.

OO has an universal application, hence few clues on what aspects or phenomena that should be modelled are given. Therefore, many approaches combine $\mathrm{OO}$ with some other perspective, e.g.:

- A metaphor, like regarding workers as skilled craftsmen in a workshop. Models are then made of their tools and materials (Bürkle, et al. 1995).

- An ortogonal modelling technique that explains an object oriented model (e.g. Jacobson, et al. 1994). 
- An existing non OO framework, seen in an object oriented perspective (e.g. Wang 1995).

- Implications from a social theory, (like articulation work (Strauss 1993)) (e.g. Carstensen, et al. 1995).

There is a potential problem when only one, or a few, perspectives are used when analysing a current work practice and how the computer systems mediate this practice. Due to differences in scope, concepts, and inherent perspectives combination of various OOA approaches may be difficult. The research question of this paper is therefore: How could some social theory on artefacts and work be used to classify OOA approaches, in terms of what aspects of work they address.

Generally, new approaches to modelling work are balancing between two pitfalls, on the one hand they contribute to more powerful representational forms in respect to work arrangements, but on the other hand they should recognise that abstraction and formalisation of work practices inevitably left something out of the representation. As Bannon (1995) claims:

Models are thus seen [...] as interpretations, as constructions, which for some purposes, under certain conditions, used by certain people, in certain situations may be found useful, not true or false. (ibid, p. 67)

\section{Computers Incorporated into Work Arrangements}

This section presents a perspective on computers incorporated in work arrangements, based on activity theory, developed in Fjuk, et al. (forthcoming).

Activity theory originated as a psychological theory giving a notion of context to human actions in the world, in the sense that an activity orients a subject in an objective world. Central to this interaction is a motive, which is fulfilled by means of the activity and thus explains why an activity exists (Leontjev 1983).

The subject does not relate to the objective world directly, but through artefacts like concepts, heuristics, and tools. One of the claims of activity theory is that the nature of any artefact can be understood only within the context of human activity - by identifying the ways people use this artefact, the needs it serves, and the history of its development (Kaptelinin 1996). 
An activity constitutes a hierarchical structure with inner dynamics, transformations and its own development. (Leontjev 1983). The driving force behind activity, action and operation is different, as can be seen in Figure 1:

Figure 1. The internal side of an activity, along with corresponding driving forces (ibid.).

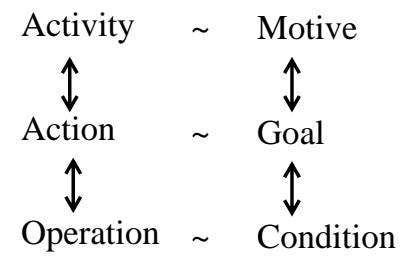

An activity is realised through goal-oriented processes, termed actions. An action can realise different activities as the given action may fulfil different motives. Before an action is performed, it is planned by a conscious subject. Actions are realised through operations, that face conditions in the objective world. Operations are typically initiated unconsciously-often even the collection of operations that accomplish the action is selected without explicit decision. The 'automatic' choice and routinesed performance are possible only for a knowledgeable and experienced subject. The development may be described in terms of habitualisation and institutionalisation (Berger and Luckmann 1966). But once acquired, this ability appears as a competence for situated action. Development of cognition is thus a process moving actions to operations, and operations into actions (e.g. instances of breakdowns). As the degree of routinisation increases, the action is moving towards operation.

Engeström (1987) presents an extension to Leontjev's model of activity, with three interacting entities (the individual, the object and the community) in order to analyse the social phenomenon of human activity. The objective of the model is to take the social context of human activity, by including rules of communication and division of labour. The model is illustrated in Figure 2. The upper triangle of the model illustrates Leontjev's basic interpretation of human activity. The two others represent the collective aspects of human activity. 
Figure 2. The four aspects of collective activity

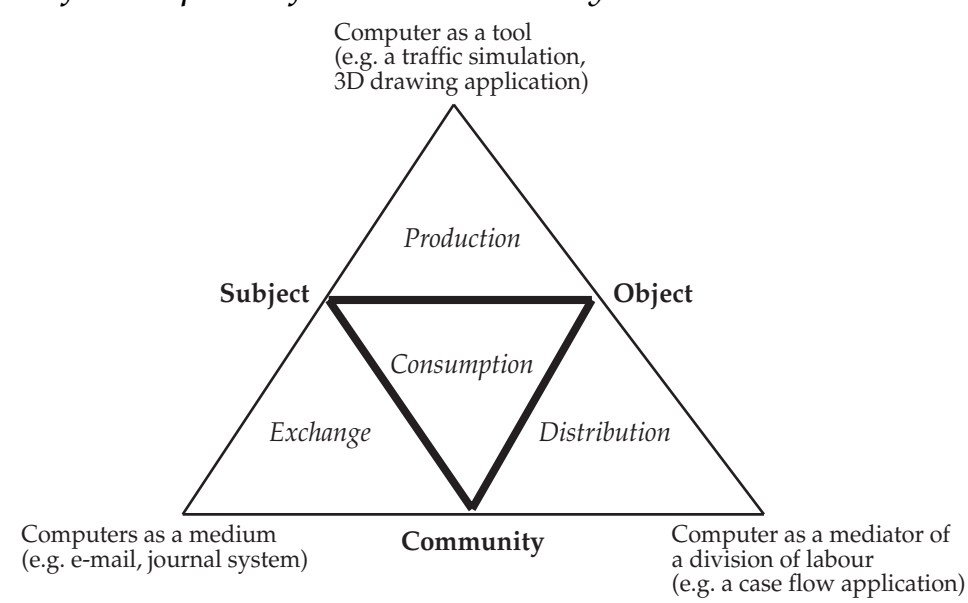

- Production denotes the relationship between subject (a human) and object. The relationship is mediated through (computer) tools.

- Distribution denotes the relationship between community (e.g. the workgroup or the employees in the organisation) and an object. This relation is mediated through the division of labour. The computer may be regarded a mediator of this division of labour, e.g. that coordination of work, or distribution of tasks, may be done by means of the computer.

- Exchange denotes the relationship between the a subject and the community. This relation is mediated through rules of social behaviour and communication. The computer may be regarded as a communication channel in this relation. E-mail and conferencing software are examples of this role in the work context.

- Consumption is covers the use of products and/or services of the activity. This implies an outside view on the activity, e.g. how customers or citizens use the services of an enterprise.

In the model, human activity is interpreted as a dynamic interrelation between the four aspects. The extended model of human activity shows that an individual is not isolated but is a part of a community, and the activity is affected by the individual's participation within this community. 


\section{Object Oriented Analysis of Work in an Activity Theoretical Perspective}

\subsection{Two Schools of OOA}

Aristotle, in the classical Poetics, has a useful distinction between the formal cause and material cause of a thing. The formal cause of a thing is the form of shape of what it is trying to be. The material cause of a thing is what it is made of (Aristotle sited in Laurel 1993). (There are also two other causes, the end cause and the efficient cause, but they are not used here.) This distinction can be used to explain the difference between what in this paper is referred to as the physical modelling and the role modelling school of object oriented analysis. A similar distinction is made for object oriented programming by Madsen (1995), termed the modelling and the reuse school.

\section{The Physical Modelling School}

The modelling school (also known as the Scandinavian school) of object oriented programming is developed with real-world modelling in mind, were objects and classes in the models represent phenomena and concepts in the real world (Nygaard and Dahl 1981; Madsen, et al. 1993). Thus, the executing program is regarded a physical model, simulating the behaviour of the real world (Madsen and Møller-Pedersen 1988).

This idea, originated in a programming context, was later applied in many object oriented analysis approaches (e.g., Coad and Yourdon 1991; Mathiassen, et al. 1993). Due to the focus on modelling the real world, the approaches have poor support for representing how's, i.e. the collaboration among objects to do some job, or the organisation of objects in a large system.

\section{The Role Modelling School}

The reuse school of object oriented programming is developed with organisation of software systems in mind, were collaboration between objects and their responsibility in respect to the operations of the system are focused (see e.g. Goldberg and Robson 1983). Some object oriented analysis approaches are based on this view, and hence focus on collaboration and responsibilities of objects (Rubin and Goldberg 1992; Høydalsvik and Sindre 1993; Reenskaug, et al. 
1996). Due to this focus, these approaches are suited for modeling aspects of the application domain, like the work organisation, but they are weak on conceptual modelling of the problem domain.

\subsection{Mediating Action and the Aspects of Work}

An activity orients a human in an objective world (c.f. Section 3). In a collective activity there are four aspects, each mediated by instruments like tools, media and the division of labour. These artefacts should be physically modeled, since they are phenomenta and concepts in the real world.

The realisation of production, by means of exchange and distribution is more focused toward the organisation of workers and their roles in respect to the work, and the communication needed to coordinate, inform and learn. Thus mediating this organisation by means of the computer, the communication and responsibilities of the objects must be represented. This is the material cause of the activity, and should be represented using role modelling.

\section{Production}

This aspect expresses the individual workers relation to their work. The computer mediates the problem domain, giving the worker clues on the structures and state of the object of work, thus enabling planning, selection of tools and procedures and giving context of the work in the total work arrangement. Thus, it is appropriate to make physical models that mediate the real world.

At the same time the worker is a part of a work organisation, and must interpret his/her responsibilities in relation to the collective activity. This interpretation results in individual actions that realises part of the activity. Role modelling is appropriate to represent the relationships between the worker as an actor, and the role (s)he has.

\section{Distribution}

The division of labour is necessary to organise and coordinate the different actions of the individual. Distribution is usually operationalised using a role concept, in the sense that the work is divided among roles, and that each role has some responsibility for a part of the whole job to be done. This perspective is also found in the role modelling school. 
However, various artefacts mediate the distribution of labour, like organisations, projects, units, and groups. Also artefacts like schedules, plans, and routines may mediate this aspect. Hence also physical models have a role in this aspect.

\section{Exchange}

This aspect expresses communication among workers in order to get the job done. Representing the communication patterns is an important part of the role modelling school. Techniques like IDEF0 (IDEF0 1993) are used to capture the interaction among objects. In an object oriented context, the interaction consist of messages sent from one object that trigger some action in another object.

Also in this aspect we find artefacts that mediate the communication, like shared objects and communication channels. It is appropriate to make physical models of such artefacts.

\section{Consumption}

This aspect expresses the use of products or services made in production. Although the author have not identified any object oriented approaches that explicitly address consumption, it is believed that this area will become more important to model as customers use computers to access the outcome of production (e.g. through a www or edi interface). It seems appropriate to use physical modelling, because the computers should mediate the outcome of production to the customers, not the internal organisation of work.

\section{Explaining Selected OO Approaches}

This section uses the theoretical framework and the operationalisation that was developed in the previous sections, to explain some approaches that have been reported used to analyse the application world. General object oriented approaches with no reports on how work arrangements should be modelled are not included.

\subsection{The Tools and Materials Approach}

Bürkle et al. (1995) use general object oriented languages, but have applied a tools and materials metaphor as a pragmatic guideline for analysis and design of interactive systems to support office work. This metaphor is motivated by an intuitive conceptual division between objects into those that are worked on and those that are means of work. This view corresponds to the production aspect, with the 
tools and materials as mediators between the worker and the work. The approach belongs to the physical modelling school. This approach does not address work arrangements.

\subsection{OOA (Aalborg)}

This is a general object oriented analysis approach (Mathiassen, et al. 1993) in the physical modelling school, it is included here because Carstensen et al. (1995) and Krogh (1996) have used it to model cooperative work arrangements. The technique was useful for specifying the structural properties of coordination mechanisms as classes and objects. However, the dynamic properties of coordination mechanisms reflecting interaction between actors are not easily expressed (Carstensen, et al. 1995, p. 115). Krogh (1996) reports: “The strengths of the object oriented analysis approach lies in the structural powerful techniques, but the means for capturing dynamics are weak; mainly the support for modelling the application domains needs strengthening" (ibid. p. 337). These studies indicate that conceptual modelling alone is not sufficient when modelling work arrangements.

\subsection{OO Task Analysis}

Wang (1995) applies an object oriented perspective on task analysis, which is a non $\mathrm{OO}$ framework. The author distinguishes between computer tasks and human tasks. A task can be aggregated by subtasks. Detailed accounts of how a human uses a computer system can be made, and the approach is suitable for modelling production. Cooperation or responsibilities are not addressed.

\subsection{Use-Cases}

A use case (Jacobson, et al. 1994) is developed orthogonal to object models, as external views of the system. A use case defines a systems behaviour for a user for a given task. A use case model will not express concurrency, as use-case transactions are atomic and serialized (Jacobson 1995, p. 319). Thus it is difficult to express interdependency among workers in a use-case, which is necessary to address cooperation, but it is suitable for modelling one workers actions in order to realise part of the production.

\subsection{Object Behaviour Analysis (OBA)}

This approach (1992) emphasises what takes place in the system, called the system behaviours. Who initiates and who participates in these behaviours should be identified, and these objects are used as 
a basis for understanding the roles of different aspects of the system, and which parts of the system must take responsibility for providing services and managing system information (ibid, p. 48). This approach focuses on the work arrangement itself, and does not address physical modelling of some part of the application domain. Thus it supports representing the actions of exchange and distribution.

\subsection{Object Oriented Role Analysis and Modelling (OORAM)}

According to Reenskaug et al. (1996) objects can be thought of as clerks with in and out baskets, a private data file and book of rules. They cooperate through messages (ibid. p. 6). Høydalsvik and Sindre (1993) use OORAM to model organisational information systems. Focus is put on what roles people and phenomena in the application domain play in different contexts. Thus, OORAM supports representing exchange and distribution.

\section{Conclusions and Future Research}

A theoretical framework for OOA of work with computers, based on activity theory, is proposed.This paper suggests that a combination of two schools of OOA is necessary to address both the problem domain and the application domain. Physical modelling is suited for modelling how the computer mediates a work arrangement, in terms of tools, communication channels, shared materials etc. Role modelling is suited for modelling the responsibilities the workers have in respect to the work arrangement, this include the cooperation between workers in order to get the job done.

It is fair to conclude that none of the selected OOA approaches takes all the aspects of work into full account. However, there seem to be a rich potential for combining the best ideas of the various approaches.

Future work will explore the possibility to develop an OOA approach based on activity theory, that will explicitly combine physical modelling and role modelling.

\section{Acknowledgements}

Joan Greenbaum, Jens Kaasbøll and Leikny Øgrim joined me as members of the system development team doing the needs assessment that inspired this theoretical work. Kristen Nygaard, Haakon 
Bryhni, Dag Sjøberg, Birger Møller-Pedersen, Gisle Hannemyr, Else Nordhagen and Jan Erik Ressem gave useful comments to the ideas presented here.

\section{References}

Bannon LJ (1995) The Politics of Design: Representing Work. Communications of the ACM 38 (9), pp. 66-8.

Berger PL and Luckmann T (1966) The Social Construction of Reality - A Treatise in the Sociology of Knowledge. Penguin Books.

Bürkle U, Gryczan G and Züllighoven H (1995) Object-Oriented System Development in a Banking Project: Methodology, Experiences and Conclusions. Human-Computer Interaction 10, pp. 293-336.

Carstensen PH, Krogh B and Sørensen C (1995) Object oriented Modelling of Coordination Mechanisms. In Dahlbom B, Kämmerer F, Ljungberg F, Stage J and Sørensen C (eds.) Proceedings of The 18th Information Systems Research Seminar in Scandinavia (IRIS'18) (Gjern, Denmark), Gothenburg Studies in Informatics, Report 7.

Coad P and Yourdon E (1991) Object Oriented Analysis. Yourdon Press, NJ.

Engeström Y (1987) Learning by Expanding. An Activity-theoretical approach to developmental research. Orienta-Konsultit Oy, Helsinki.

Fjuk A, Smørdal O and Nurminen M (forthcoming) Computer-Mediated Collective Action.

Goldberg A and Robson D (1983) Smalltalk-80, The language and its implementation. Addison-Wesley, New York.

Høydalsvik GM and Sindre G (1993) Object-Oriented Role Modelling for the Analysis and Design of Organisational Information Systems. In Proceedings of $26^{\prime}$ th HICSS , 3, pp. 159-68.

IDEF0 (1993) Software Standard Integration Definition for Function Modelling (IDEF0). Federal Information Processing Standards Publication 183.

Jacobson I (1995) The use-case Construct in Object-Oriented Software Engineering. In Carroll JM (ed.) Scenario-based design: envisioning work and technology in systems development. Wiley, New York.

Jacobson I, Ericsson M and Jacobson A (1994) The Object Advantage - Business process reengineering with object technology. Addison-Wesley.

Kaptelinin V (1996) B Activity Theory: Implications for Human-Computer Interaction. In Nardi BA (ed.) Context and Consciousness. Activity Theory and Human-Computer Interaction. The MIT Press, Cambridge, pp. 103-16.

Krogh B (1996) Object Oriented Analysis of Groupware Applications. In Wrycza S and Zupancic J (eds.) Proceedings of The Fifth International Conference Information SYstems Development - ISD'96 (Gda'nsk, Poland).

Kaasbøll JJ and Smørdal O (1996) Human Work as Context for Development of OO-Modeling Techniques. In Brinkkemper S (ed.) IFIP WG 8.1/8.2 working conference on principles of method construction and tool support (Method Engineering' 96) (Atlanta, USA), Chapman \& Hall, pp. 111-25.

Laurel B (1993) Computers as theatre. Addison-Wesley Publishing Company, Reading, Mass. 
Leontjev AN (1983) Virksomhed, bevidsthed, personlighed (In Danish). Forlaget Progress, Denmark.

Madsen OL (1995) Open Issues in Object-Oriented Programming. Software Practice and Experience 25 (S4).

Madsen OL and Møller-Pedersen B (1988) What Object-Oriented Programming may be - and what it does not have to be. In European Conference of ObjectOriented programming (ECOOP'88) (Oslo, Norway), pp. 1-20.

Madsen OL, Møller-Pedersen B and Nygaard K (1993) Object Oriented Programming in the BETA Programming Language. Addison Wesley.

Mathiassen L, Munk-Madsen A, Nielsen PA and Stage J (1993) Objektorienteret analyse (in Danish). Marko, Aalborg.

Nygaard K (1986) Program Development as a Social Activity. In Kugler H-J (ed.) Information Processing 86 (Amsterdam), North-Holland, pp. 189-98.

Nygaard K and Dahl O-J (1981) The development of the SIMULA languages. In History of Programming Languages. Association for Computing Machinery, pp. 439-94.

Nygaard K and Sørgaard P (1987) The Perspective Concept in Informatics. In Bjerknes G, Ehn P and Kyng M (eds.) Computers and Democracy: A Scandinavian Challenge. Avebury Gower Publ. Comp. Ltd, Aldershot, pp. 371-93.

Reenskaug T, Wold P and Lehne OA (1996) Working With Objects: the OOram Software Engineering Method. Manning, Greenwich.

Rubin KS and Goldberg A (1992) Object Behavior Analysis. Communications of the ACM 35 (9), pp. 48-62.

Simone C and Schmidt K (1993) Computational Mechanisms of Interaction for CSCW. COMIC, Esprit Basic Research Project 6225, Lancaster University.

Smørdal O (1996) Soft Objects Analysis, A modelling approach for analysis of interdependent work practices. In Patel D and Sun Y (eds.) 3rd International Conference on Object-Oriented Information Systems (OOIS'96) (London, UK), Springer-Verlag, pp. 195-208.

Strauss A (1993) Continual Permutations of Actions. Aldine de Gruyter, New York.

Wang S (1995) Object-oriented task analysis. Information \& Mangement 29 , pp. 33141. 